\title{
ARCHIVES PHOTOGRAPHS IN PHOTOGRAMMETRY TO ASSESS THE CONSERVATION STATE OF MONUMENTS: THE WHITE CHAPEL OF SESOSTRIS I
}

\author{
L. Bontemps a, S. Mirabaud ${ }^{b}$, F. Guéna ${ }^{c}$, A. Lehoerff a \\ a Department of History, Héritage/s UMR9022, University of Cergy-Pontoise, Cergy, France \\ (laura.bontemps@cyu.fr; anne.lehoerff@cyu.fr) \\ b Department of Research and Study, INHA, Paris, France \\ (sigrid.mirabaud@inha.fr) \\ c Map-Maacc UMR3495, ENSAPLV, Paris, France \\ (francois.guena@paris-lavillette.archi.fr)
}

\section{Commission II}

KEY WORDS: Photogrammetry, Cultural Heritage, Analog Photographs, Archives, Monuments, Comparison, Conservation, Data Processing Techniques.

\begin{abstract}
:
Nowadays professionals from the Cultural Heritage field make use of Digital technology in all its diversity as a tool to conduct various type of work : archeological and architectural survey, monitoring, conservation programs, historic researches. This paper describes the first steps of a $\mathrm{PhD}$ research aiming at exploring the use of analog photographs from the French-Egyptian center for the study of Karnak Temples (CFEETK) in photogrammetry. The goal is to compare previous condition state of monuments in the 20th century with their contemporary condition and to introduce 3D model in correlation databases. The paper presents the context of the study and the complex of Karnak temples then the set of archives photographs that are used and how they are processed. At this stage, sets of analog photographs from the White Chapel were used in Agisoft Metashape combined with contemporary photographs to provide visuals from the condition of the monument after its restoration in 1985.
\end{abstract}

1.

\section{INTRODUCTION}

In the field of cultural heritage whether you are a conservator, photographer, historian or an archeologist, documentation and digitization has become a key point in our day-to-day work life. Through the last decade, the recording of heritage assets has happened to be a challenge as well as a necessity. Because of armed conflicts (Al Khalil, Grussenmeyer, 2019)(Bitelli \& at., 2017), climate changes and flooding (Falkingham \& at., 2014) or natural decay, we need to safeguard documentation on cultural assets, for research and study as well as potential future conservation work. Democratization of digital technics and photogrammetry softwares leads to question the purpose of our work when we produce 3D models. Digitization of a cultural assets should be done with specific agenda before-hand.

Since the Venice Charter in 1964, international Cultural Heritage guidelines have established photography as a mandatory step in documentation of monuments. In 1858, the German architect Albrecht Meydenbauer was ahead of his time since he already emitted the idea to use photography as a mean to document and preserve information about monuments. The inventor of photogrammetry is also the originator of stereoscopic pairs of photography of Heritage monuments, photographs that have been re-exploited since then (Hemmleb, 1999). At the same time, photography was promoted in archeology as a way to scientifically depict discoveries (Collet, 1996) and to achieve higher accuracy than drawings and watercolors as it was usually done at that time.

Except for their documentation purposes, archives photographs have gone through a silent journey for decades before they gained recent recognition other than a 2D documentation, both as data sources and heritage artefacts. Since the early 2000s they are more and more considered as a potential source of historical and metric data on cultural heritage assets and different methods have tried to use them as such. Historical photogrammetry derives from this idea and previous researches have been conducted on this topic. The well-known case of the Buddhas of Bamiyan (Grün \& at., 2004) marked a step in the use of photographs that were not meant for photogrammetry purposes.

The use of historical photographs is counterintuitive to the recommendations and prerequisites for photogrammetry applications. As it was stated by the several teams who got to work on it, analog photographs do not overlap correctly, they bare no metadata about the camera calibration, their quality can be poor or at least very heterogeneous and they can be altered by time and storage conditions. Still, case studies have proven the possibility to process archives photograph with the means of orthorectification (Al Khalil, Grussenmeyer, 2019), mixedsources data (Condorelli, Rinaudo, 2018) and also Structurefrom-Motion softwares (Bitelli \& at., 2007)(Falkingham \& at., 2014)(Al Khalil, Grussenmeyer, 2019)(Bontemps, Guéna, 2019). As a way to achieve higher accuracy and to compensate for missing parts within the archives, the implementation of contemporary data (photographs, laser-scanning) with analog photographs has also been tested (Maiwald \& at. 2017) (Bevilacqua \& at., 2019) to help with calibration within softwares.

We aim at developing a protocol for the use of different sets of historical photographs in photogrammetry softwares, in order to compare the models issued from archives photographs to the actual state of preservation of the monuments. The comparison of timed models will allow the assessment of the evolution of previous conservation works, their influence and behavior on the monuments and the evolution of alterations of original materials such as stone and pigments. The protocol we try to establish should be adaptable to various scenarii in order to be reused on other Cultural Heritage monuments. As we have the opportunity to do an extensive research, we want to establish a methodology that can be protean and that allows heritage 
professionals to use the information of the past for a better conservation in the future.

These photogrammetry, the one issued from analog photographs (historical model) and the other from present digital photographs (contemporary model) will be integrated into correlation databases to help monitor monuments. In short, this doctoral research aims to develop an interdisciplinary effective tool for collaborative management of cultural heritage, to enhance the processing of data among and between each categories of professionals, insuring that past and present datasets will pass on to future colleagues.

\section{2.}

\section{KARNAK AS A RESEARCH FIELD}

\subsection{An open-air museum with interdisciplinarity as a basis}

Unlike other archeological monuments of Egypt, the complex of Karnak has never ceased to be used by human beings. Several Roman imperial edicts lead to the complete abandonment of the pagan cult at the dawn of the fourth century ACE. After the slow cessation of the pharaonic cult, Karnak was somehow abandoned to whomever wanted to live inside it. During the late Graeco-Roman period, some parts of Karnak were dismantled, as for the obelisk of the West temple and the one from the VIIth pylon under the reign of Emperor Constantine.

Even though the precise datation is unclear, after some while, Karnak has been invested by Coptic. Archeological surveys have put in evidence that Karnak was used and fragmented in several spot for households as well as for the Christian cult (David R., 2016).

Seemingly the complex was never completely abandoned and must have been inhabited throughout centuries, until it was " discovered " by Europeans in the 18th century. The first archeological excavations took place in 1818 under JeanJacques Rifaud, a French sculptor who is acknowledged as the first excavator in Karnak. Europeans and especially French over time, understood the benefits that lied in the study of Karnak temples and it was a race against time since some parts of the complex were being destroyed in the 19th century.

Quickly, Karnak temples became a place of study, excavation and reconstruction for egyptologist and archeologist: as a very complex set of monuments, it has been well established from the beginning that work at Karnak can only be an interdisciplinary one, with architects, archeologists and very rapidly photographers (Traunecker, Golvin, 1984). Early photographs have thus been taken when the monuments were still partially ruined, and then continuously throughout the years, witnessing the evolution and the reconstruction work that have taken part in this multi millenary complex of temples.

\subsection{Selecting the monuments in Karnak}

The complex of temples in Karnak is one of the largest religious heritage from Antiquity. Its construction took place over three different millennia, roughly from the Middle Kingdom (c.2040-1782 BCE) until the Ptolemaic era (Graeco-Roman period) (332 BCE-323 ACE) and as it is, a maze of monuments embedded one with another (figure 1). In order to pursue construction projects from one king to another, some of the monuments were even teared down to build new ones with the new King's iconography.

As part of this research, we had to narrow our study down to independent buildings inside Karnak. As for now, two monuments have been selected to elaborate the treatment protocol. They were chosen according to the following list of criteria:

- it must have undergone one or several conservation work,

- photographs from the archives must still exist and for each important modification of the monument,

- alterations and decay can be observed nowadays.

In the light of these, our interest has focused on the Kiosque of king Taharqo and on the White Chapel of Sesostris the 1st. For clarity purpose in this paper, we will only develop the the case of the White Chapel.

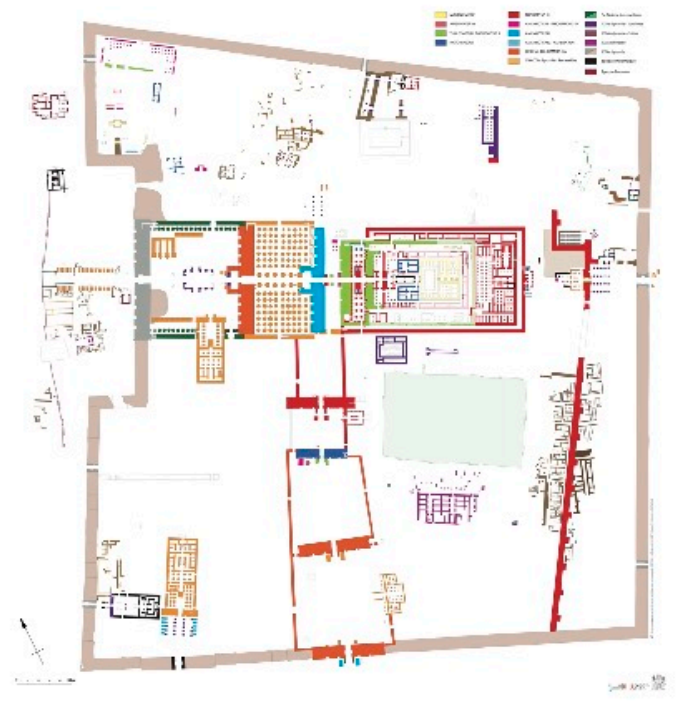

Figure 1. Chronologic map of Karnak.

\subsection{The White Chapel of Sesostris I}

The White Chapel of Sesostris I is one of the oldest building still preserved in the complex of Karnak Temples, as it was built during the reign of Sesostris I from Dynasty XII (c.1962-1928 $\mathrm{BCE})$. Its construction might have taken place for the pharaoh's first jubilee but daily-cult has also been rendered.

Entirely built in white limestone, the Chapel (figure 2) offers a very distinctive architectural set of features and served later on as a model for posterior constructions inside Karnak. According to Egyptians codifications, the base, East and West doors lintels and doorjambs are in relief en creux, as to express their belonging to external modules of the architecture, whereas the architraves and the face of pillars on the outside are in basrelief, to express the fact that they are supposed to be « inside » the walls of the sacred space.

After the reign of Sesostris I the Chapel was still in use and we have evidence of it under the reign of Queen Hatshepsut (1498-1483 BCE) (Gabolde L., 2018). Specific temporality has not been determined but sometime after during the New Kingdom (c.1570-1070 BCE) the Chapel has been deconstructed $^{1}$, probably stored in sparse blocks, only to be reemployed as a filling in the bedding of the third pylon of Karnak, erected by king Amenhotep III (1386-1349 BCE).

\footnotetext{
${ }^{1}$ we insist on the use of the verb " deconstruct », as it was not a destructive act per sé but more a respectful reuse of the stones belonging to a sacred Chapel that was no longer needed.
} 


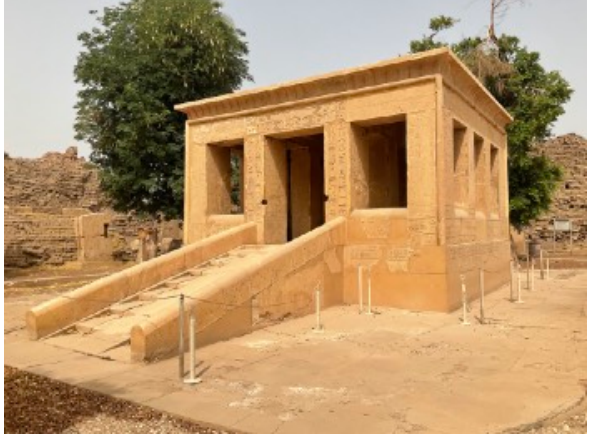

Figure 2. North-East view of the White Chapel (June 2021)

Like several other monuments in Karnak, the discovery of the first blocks of the White Chapel took place in 1927 during an extensive conservation work on the bedding of the third pylon who had proved to be unstable and endangered the Great Hypostyle hall (Chevrier, ASAE 21-37). Under the direction of Pierre Lacau and supervision of Henri Chevrier and for ten years, archeologists and egyptologists kept discovering new parts of the White Chapel allowing them to conduct its anastylosis starting in 1937.

As its precise original location is unknown, it has been decided to erect the monument in the so called "Open air museum ». This area, located in the Northern part of Karnak complex, displays the monuments (or partial construction) that can not be preserved on their original location. After an archeological survey of the area, foundations have been dug to allow the anastylosis of the Chapel (figure 3). Henri Chevrier describes all the steps of this work and explains the methods used for large restitution as well as for small fillers (Lacau P., Chevrier H., 1956). Unfortunately, mapped report were not a prerogative in conservation work at that time, so one can only observe through photographs where the fillers were placed on the reliefs.

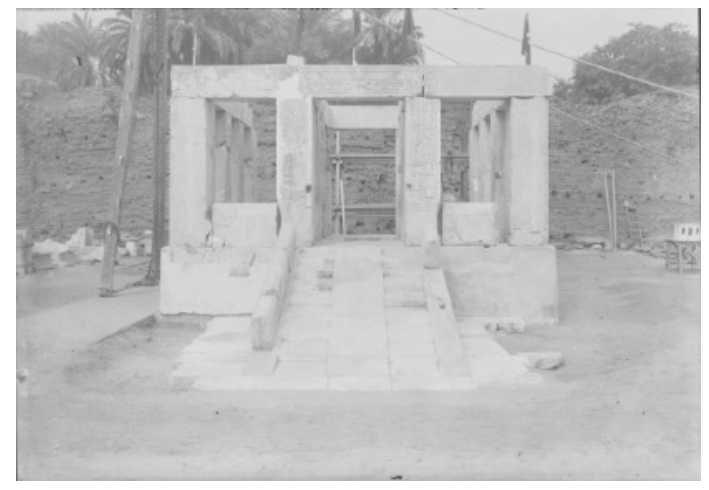

Figure 3. Glass plate photograph during the anastylosis from Henri Chevrier in $1938\left(n^{\circ} 16840\right)$.

In 1985 a new conservation program was conducted on the Chapel by the conservation team of the CFEETK. As described by conservators Daniel Lefur and Claire Scemla, plaster mortars from Henri Chevrier's work and large-scale restitution were altered. Hesitating between doing a clean slate and removing all the plaster from Chevrier or considering them as historical parts of the monuments, choice was made at that time to remove only the filling that were in bad condition and replace them with cement mixed with lime. Nevertheless, the larger restitutions made with plaster, cement and wood in 1937 were completely removed, to be replaced either with limestone (as for the architrave on the West facade) or with a brick core covered with cement.

In the archives, written or drawn, from the conservation of 1985, there is no alterations mapping (detailed condition report) nor mapping of the work of Chevrier and its fillings. As it is, it is no easy task to know exactly which parts of Chevrier's work has been removed in 1985, except for the help of archives photographs and detailed in-situ observations of the reliefs (figure 4).

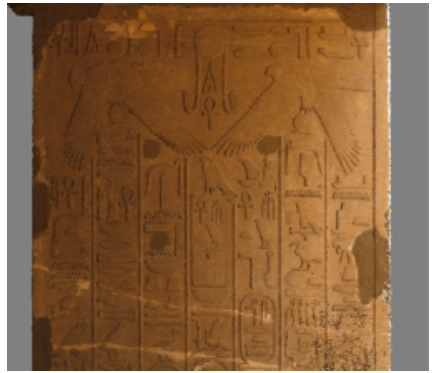

Figure 4. Dense point cloud of relief 9, coexistence of cement mortar (1985) and plaster fillings (1937-41).

\subsection{Archives photographs from Karnak at the CFEETK}

The French-Egyptian center for the study of the temples of Karnak (CFEETK) is an over fifty-year-old institution, dedicated only to the conservation and the study of the complex of Karnak. It was preceded by the long lasting Service des antiquités égyptiennes (Egyptian antiquities service - SAE) historically led by French from the end of the 19th century until the early 1950s. The CFEETK, founded in 1967, has collected the photographs from the SAE to conserve them in Karnak. Therefore, they still possess a large collection of glass plates photographs which were later completed with negatives and diapositives taken throughout the 20th century. For documentation purpose, photographs have been digitized by the photographers' team since 2009. The Karnak project launched in 2013 allowed to pursue the digitization of the photographs collection to insert them in an online database (http:// www.cfeetk.cnrs.fr/archives/).

\section{RECORDING PROCESSING THE DATAS}

\subsection{Inventory and digitization of archives photographs}

Previous trials of historical photogrammetry have already pointed out the inherent difficulties of this method regarding the quality of archives photographs and the different challenges they oppose (Bitelli \& at., 2017)(Condorelli, Rinaudo, 2018). The photographs from Karnak did not differ on that point, as we are confronted to lack of information about the camera calibration, variations in quality, overexposure and/or underexposure and last but not least the decay of the photographs mostly caused by their storage in the south of Egypt or by the photographical technic by itself (in this case we think of diapositives which bare specific discoloration).

The first selection of the archives photographs was first made on the CFEETK database (http://www.cfeetk.cnrs.fr/archives/). During their digitization for the Karnak project, the archives were modified with the scanner software, varied parameters such as brightness, contrast, clarity. As the native files were not 
saved, we ought to digitized the archives by ourselves to gain control on any modification possible. Thereby, a second selection process was made while the reprography of the photographs and you can see in table 1 the type and final number of selected photographs of the White Chapel. As part of our research process, in future steps, we would like to compare the use of digitized photographs from a scanner (in this case an Epson V550 used for digitization and storage on archéogrid) and photographs digitized with reprography technic performed in 2021 with a Fujifilm XT-3 and a macro lens the $80 \mathrm{~mm}$ f2.8. We chose this lens for its high definition and very low distortion. The twenty-four glass plates photographs from Chevrier's era were not re-digitized for our research as their current state of conservation doesn't allow handling until they are restored.

\begin{tabular}{|c|c|c|c|}
\hline Collection & Size and/or type & Date (range) & $\begin{array}{c}\text { Number of } \\
\text { images }\end{array}$ \\
\hline Chevrier & Glass plates & $1937-1941$ & 24 \\
\hline $\begin{array}{c}\text { CFEETK (Chéné, } \\
\text { Perrot, ) }\end{array}$ & $\begin{array}{c}24 \times 36 \mathrm{~mm} \\
\text { diapositives }\end{array}$ & $1980-1991$ & 126 \\
\hline CFEETK (Bellod) & $6 \times 6 \mathrm{~cm}$ negatives & 1985 & 18 \\
\hline Barguet & $6 \times 7 \mathrm{~cm}$ negatives & & 12 \\
\hline CFEETK (Chéné) & $6 \times 7$ diapositives & 1995 & 48 \\
\hline CFEETK (Chéné) & $13 \times 18 \mathrm{~cm}$ negatives & 1995 & 19 \\
\hline
\end{tabular}

Table 1. Collected historical photographs of the White Chapel from the CFEETK archives.

\subsection{Inquiry on old cameras at Karnak}

After their proofing the photographs are uncalibrated but they bare EXIF from the camera used for reprography. To avoid miscalibration, we first had to remove these metadata. After the basic necessary development treatment of the photographs in Adobe Lightroom (invert negatives, reframing) the export were made in .tiff without metadata from camera and lens.

One of our research hypothesis stands on the fact that if we were able to recover calibration data for the archives photographs, we could achieve better adjustments inside photogrammetry softwares.

Thus, an extensive research has been carried out about the history of photography, photographers who came to Karnak (amateurs and professionals) and the equipment used by egyptologists and archeologists on the field. We were able to make a list of plausible focal length and cameras. Then, the batch of historical photographs is copied as many times as we have hypothesis for the camera calibration. For example, if we have three lenses that were likely in use for a particular set of photographs, we make three new copies of the set of photographs and implement a different set of metadata.

The metadata are implemented in the core of the digitized photographs. This is rendered feasible thanks to an open source plugin called LensTagger (developed by Dirk Essel) added to the software Adobe Lightroom. LensTagger allows us to implement any data we need about the analog photographs, as though we made them ourselves. Each copied set is saved with the new metadata, ready to be tested in photogrammetry softwares that will acknowledge the new EXIF.

\subsection{Photogrammetry of the current state of the Chapel}

Alongside the work on archive photographs, the recording of the current state of the White Chapel has been conducted in the open air museum of Karnak. The dimensions and architecture of the Chapel (figure 4 \& 5) required the installation of scaffoldings for the facades and the help of tripod and monopod to photograph the ceiling and the sixteen pillars inside.

The camera used is a Fujifilm XT-3 with a $35 \mathrm{~mm}$ lens $\mathrm{f} 2.8$ (equivalent to a $50 \mathrm{~mm}$ lens)

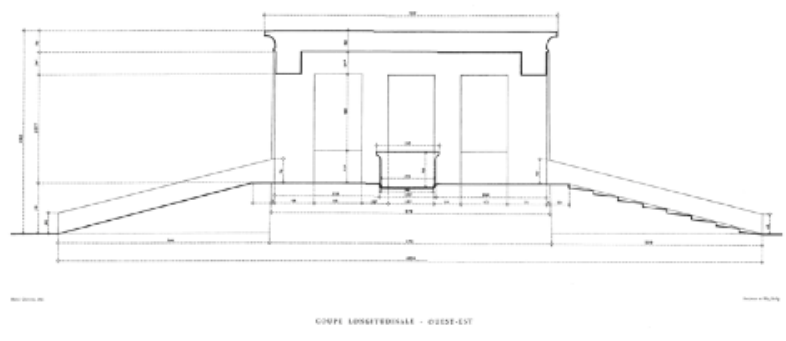

Figure 4. Longitudinal section of the White Chapel.

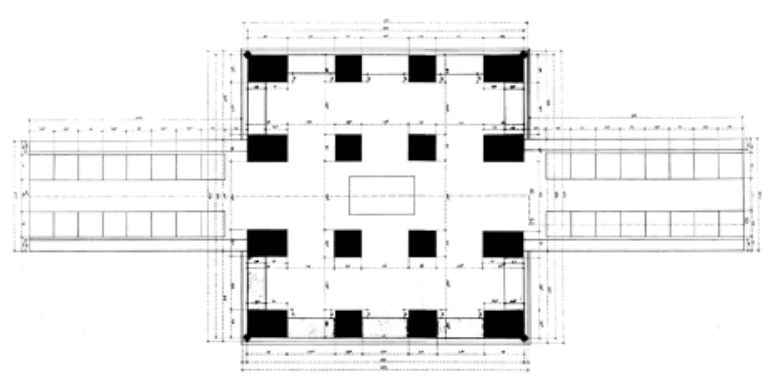

Figure 5. Layout of the White Chapel.

The photogrammetry reconstruction is calculated with the commercial software Agisoft Metashape in high resolution. The photogrammetry serves several purposes in the case of the White Chapel: for comparisons with previous states, for future conservation reports and to help referencing for the historical photogrammetry reconstruction.

\section{DATA PROCESSING FOR HISTORICAL PHOTOGRAMMETRY}

At this stage of our research, trials have been conducted only in the software Agisoft Metashape, an SfM commercial software. We first tried a batch of 12 historical photographs from the Eastern and Northern facade (figure 6). They consist of five diapositives $(24 \times 36 \mathrm{~mm})$ and seven black and white photographs (two in $6 \times 6 \mathrm{~cm}$ and five in $6 \times 7 \mathrm{~cm}$ ). Other problems can occur as we have different image scales and image resolution to identify points in the images (Bevilacqua \& at., 2019). According to the inquiry about camera and lens, we decided to first try this batch without calibration and to make a second experiment with implemented EXIF.

The first set of archives without EXIF will be run with automated calibration integrated within the software. Key markers must be added to help the alignment process, since overlapping between photographs is very low. Nevertheless, the result was not conclusive and so we moved on to the second set of photographs, with added EXIF. This second part of the test allowed us only to use fewer markers as we added only 15 when previously 25 were required to achieve a similar outcome. 


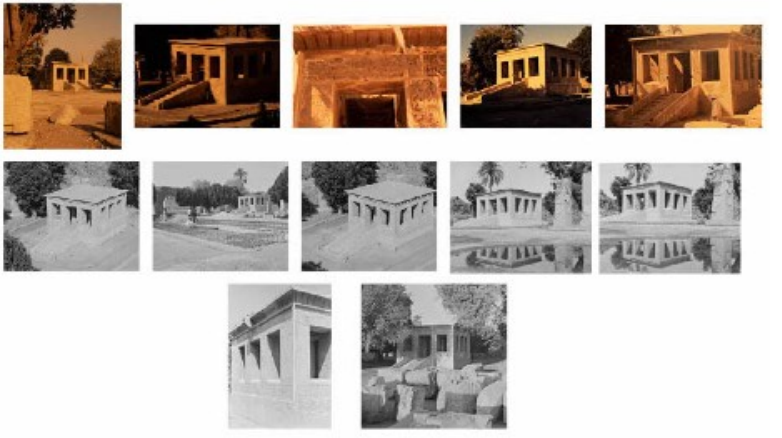

Figure 6. The twelve photographs of the East and North facade.

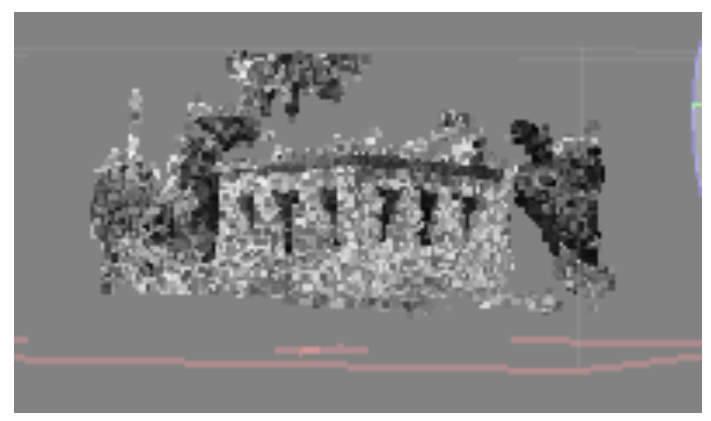

Figure 7. Capture of the cloud point from 12 archive photographs.

The number of points in the dense point cloud is still very low and accuracy is not met as we need it to be. Moreover the lack of view from the South-East angle in the archives didn't allow us to get even low accuracy from that point of view and the complexity of the stairs was also a huge obstacle when working with the historical photographs.

\subsection{The architrave D2-D2'}

After this result, we decided to conduct test on smaller parts of the monument. A photographic campaign from the architraves and the pillars of the White Chapel took place after the restoration of 1985. The archives available today for this part consists of 31 black and white negatives in $6 \times 7 \mathrm{~cm}$.

A batch of photographs from the architrave of the Northern alley inside the Chapel has been tested. The photographs from the architraves have poor overlap as they were taken for documentation purpose only and for epigraphic study (figure 8). Following the proposition of (Maiwald \& at. 2017), we aimed at implementing contemporary photographs with archives to obtain an hybrid photogrammetry. Adding the contemporary photographs, for which all camera calibration is well-known, helped with the lack of overlapping between archives. With the photogrammetry obtained from present state of the Chapel, we can add archive photographs in order to achieve better accuracy since the geometry features of the monument don't differ too much from what they were in 1985. By this method we were able to add several close range archive photographs in our batch. By adding markers between the sets of photograph, the alignment has been successful for all the archives that were introduced in the set of the architrave, after what only the contemporary photographs helping to improve the overlap were kept. For comparison purposes between the two conservation states (1985 / present), the texture of the photogrammetry can be calculated solely with the archives or solely with present pictures (figure 9). A total of 17 markers were necessary to achieve the complete alignement of the architrave D2-D2'. The central This allowed us to extract informations from the archives photograph, using the contemporary photogrammetry as a constraint to help geometric reconstruction. Nevertheless they hold important information about the state of conservation of the architraves at that time and especially about their filling (in cement and plaster) and the evolution of specific stone alterations such as scaling, salts and cracks.
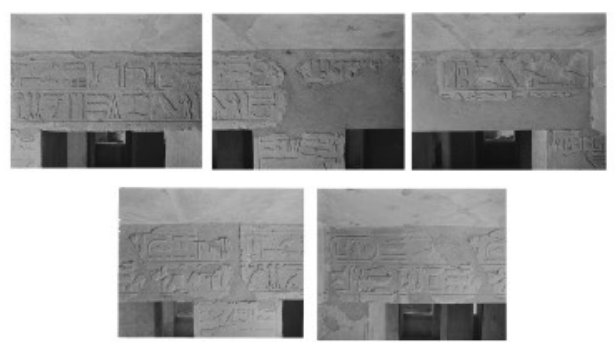

Figure 8. Photograph of architrave from 1986.

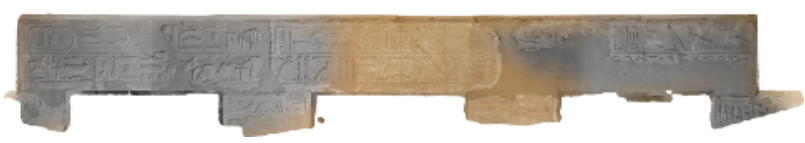

Figure 9. Orthophotography of architrave D2-D2'.

\subsection{The Northern facade}

This first conclusive result with the architrave lead us to try this method on a larger scale with the Northern facade of the Chapel. The set of close-range archives conserved for this part is composed of 6 diapositives $(24 \times 36 \mathrm{~mm})$ and 14 black and white negatives $(6 \times 7 \mathrm{~cm})$ (figure 10). As for the architrave, a low overlap is existent (figure 11) but not sufficient to achieve alignment with the archives alone. We added a batch of digital contemporary photographs to help recovering overlapping points. By adding markers (figure 12), the software has been able to align correctly all the historic recordings which have been used in the process.

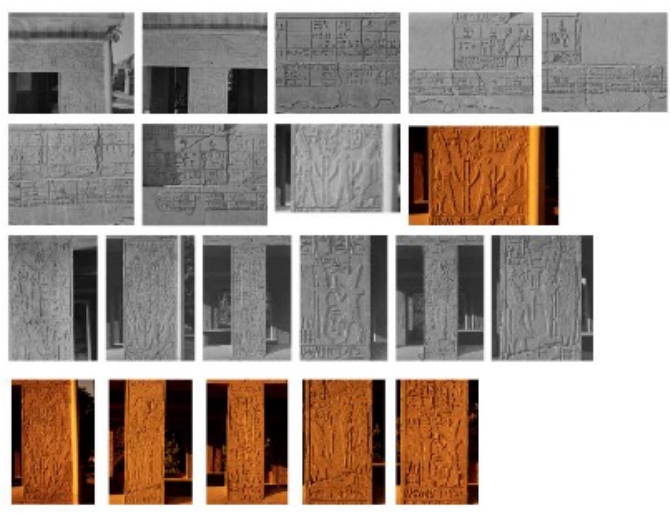

Figure 10. Photographs of Northern facade from 1986. 


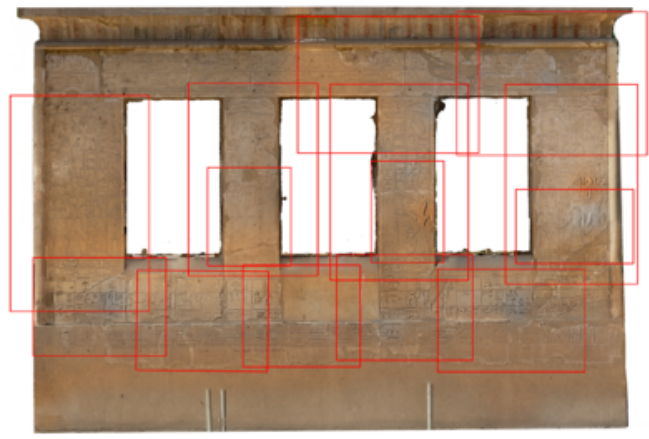

Figure 11. Orthophotography with location of archives.

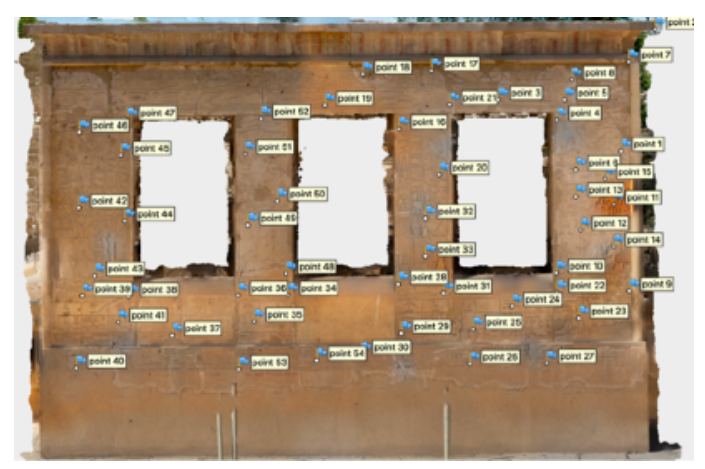

Figure 12. Location of point markers.

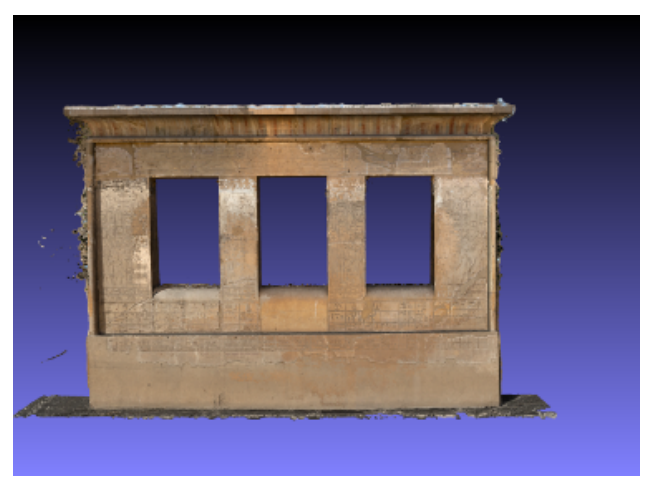

Figure 13. Resulting dense point cloud with archives photographs combined to contemporary photographs.

Except for non-documented area on this part of the Chapel, the obtained dense point cloud (figure 13) allows us to compare the conservation condition of the external reliefs of the Northern facade. Next step will be the addition of the wide-angle photographs from the North-East point of view.

\section{RESULTS AND FUTURE WORKS}

The purpose of the research presented in this paper was to build the first steps of the 3D reconstruction of how the White Chapel in Karnak looked like after its restoration in 1985, allowing it to be compared to its contemporary condition.
Following historical research about history of photography especially in Karnak - and the recording of the archives photographs, we lead first tests for 3D reconstruction with the software Agisoft Metashape. We managed to obtain first views from the White Chapel as it was in 1985 based on its contemporary geometry in the photogrammetry.

Implementing EXIF about cameras used might lead to a better calibration into photogrammetry softwares and we want to explore further their possibilities. The following steps in our research will be the trials of historical photogrammetry with the use of the software MicMac (developed by IGN France). The main advantages of this software is the larger grasp one can have about the algorithms that are used through all the processing steps (Condorelli \& Rinaudo, 2018).

The glass plates photographs which are not taken in consideration in this paper are also currently processed to achieve a reconstruction of the White Chapel as it was after its anastylosis in 1941.

From the monitoring of monument perspective, our first observations indicate modifications and alterations of the White Chapel: its original materials as well as the ones used for the previous conservation works. Our perspective is to extend the use of $3 \mathrm{D}$ models as a way to compare the different conservation conditions of the monument and to implement a collaborative follow up. This research is on-going and still at its beginning and a lot of parameters need optimization.

The establishment of the monitoring process of the Chapel in Karnak will allow the supervision of the alterations evolution and the use of correlation data bases to exploit the 3D models can lead to a very efficient communication process during future conservation works and monitoring.

\section{ACKNOWLEDGEMENTS}

Archives photographs shown in this paper are property of the CFEETK. The contemporary map of Karnak temple is also a production from the CFEETK and we would like to thanks Florie Pirou for it. The architectural plans of the White Chapel are extracted from (Lacau P., Chevrier H., 1956). All other figures are by the authors. The authors also would like to thanks the CFEEKT for its help and support during this research.

This work was supported by the Paris Seine Graduate School Humanities, Creation, Heritage, Investissement d'avenir ANR-17-EURE-0021 - Foundation for Cultural Heritage Science).

\section{REFERENCES}

Al Khalil O., Grussenmeyer P., 2019. 2D \& 3D Reconstruction workflows from archive images case study of damaged monuments in Bosra Al-Sham City (Syria).

Barreau J.-B., Lanoë E., Gaugne R., 2020. 3D Sketching of the Fortified Entrance of the Citadel of Aleppo from a Few Sightseeing Photos. Horst Kremers. Digital Cultural Heritage, Springer International Publishing, pp.359-371.

Bevilacqua M.G., Caroti G., Piemonte A., Ulivieri D., 2019. Reconstruction of lost architectural volumes by integration of photogrammetry from archives imagery with 3D models of the status quo. Int. Arch. Photogramm. Remote Sens. Spat. Inf. Sci. - ISPRS Arch

Bitelli G., Girelli A., Marziali M., Zanutta A., 2007. Use of historical images for the documentation and metric study of cultural heritage by means of digital photogrammetric techniques. XXI International CIPA Symposium. 
Bitelli G., Dellapasqua M., Girelli V.A., Sbaraglia S., Tini M.A., 2017. Historical photogrammetry and terrestrial laser scanning for the 3D virtual reconstruction of destroyed structures : a case study in Italy. Int. Arch. Photogramm. Remote Sens. Spat. Inf. Sci. - ISPRS Arch.

Bontemps L., Guéna F., 2019. La photogrammétrie numérique à partir d'archives argentiques : mise en place d'un protocole adapté à la restauration d'une niche gallo-romaine. In Situ 39.

Chevrier H., 1927-1934. Rapport des travaux de Karnak dans les ASAE 1927-1941.

Collet P., 1996. La photographie et l'archéologie: des chemins inverses. In Bulletin de correspondance hellénique. Vol.120, pp.325-344.

Condorelli F., Rinaudo F., 2018. Cultural heritage reconstruction from historical photographs and videos. Int. Arch. Photogramm. Remote Sens. Spat. Inf. Sci. - ISPRS Arch.42, 259-265.

David R., 2016. Quand Karnak n'est plus un temple... les témoins archéologiques de l'Antiquité tardive. Cahiers de Karnak 16, p.147-165.

Falkingham P.L., Bates K.T., Farlow J.O., 2014. Historical Photogrammetry : Bird's Paluxy River Dinosaur Chase Sequence Digitally Reconstructed as It Was Prior To Excavation 70 Years Ago. PLoS One 9.

Gabolde L., 2018. Karnak, Amon-Rê ; La genèse d'un temple, la naissance d'un dieu. Le Caire, IFAO.

Grün A., Remondino F., Zhang L., 2004. Photogrammetric reconstruction of the Great Buddha of Bamiyan, Afghanistan. The photogrammetric record, Vol. 19, pp. 177-199.

Hemmleb M., 1999. Digital rectification of historical images. CIPA International Symposium. Brasil. IAPRS, Vol. 32.

Lacau P., Chevrier H., 1956. La Chapelle de Sésostris Ier à Karnak, planches et monographie. Service des antiquités de l'Égypte. Le Caire. Imprimerie de l'institut français d'archéologie orientale.

Maiwald F., Vietze T., Schneider D., Henze F., Münster S., Niebling F., 2017. Photogrammetric analysis of historical image repositories for virtual reconstruction in the field of digital humanities. Int. Arch. Photogramm. Remote Sens. Spat. Inf. Sci. - ISPRS Arch. 42, 447-452.

Réveillac G., 2003. Les collections photographiques Beato, Gaddis-Seif, Adly-Leichter. Extrait des Cahiers de Karnak 11, p.515-524.

Traunecker C., Golvin J.-C., 1984. Karnak, résurrection d'un site. Paris, Office du livre.

Wilson A., Miles H., Labrosse F. \& al., 2016. Historical records, archives and photogrammetry. The historic environment : policy and practice, Vol. 7 (1). 